\title{
EFEITO DA ALTITUDE SOBRE AS VARIÁVEIS METEOROLÓGICAS EM UM TRECHO DE FLORESTA OMBRÓFILA DENSA SUBMONTANA
}

\section{EFFECT OF ALTITUDE ON METEOROLOGICAL VARIABLES IN A STRETCH OF ATLANTIC RAINFOREST}

\author{
Franciane Feltz Pajewski ${ }^{1}$, Alexandre França Tetto ${ }^{2}$, Alexandre Behling ${ }^{3}$, \\ Jaçanan Heloisa de Freitas Milani ${ }^{4}$, Andressa Tres ${ }^{5}$
}

1, 2, 3, 4, 5 Universidade Federal do Paraná, Curitiba, Paraná, Brasil-franpajewski@yahoo.com.br, tetto@ufpr.br, alexandre.behling@ufpr.br, jacanan.milani@gmail.com \& tres.andressa@gmail.com

RESUMO

\begin{abstract}
As variáveis meteorológicas podem ser influenciadas por diversos fatores e sofrerem modificações de acordo com a posição atmosférica, altitude e composição da vegetação. Os objetivos deste trabalho foram: a) caracterizar o comportamento da temperatura e umidade relativa do ar em diferentes altitudes; e b) verificar o efeito da altitude sobre essas variáveis. A área de estudo foi um trecho de FOD submontana em Guaraqueçaba, Paraná. Foram instaladas duas estações meteorológicas nas altitudes de 30 e $400 \mathrm{~m}$ (ambas na face Sul), que registraram dados de temperatura do ar e UR durante os meses de maio de 2017 a abril de 2018. A temperatura média do período variou de $20,63(30 \mathrm{~m})$ a $19,13^{\circ} \mathrm{C}(400 \mathrm{~m})$, sendo o gradiente de redução de temperatura com o aumento de altitude de 0,34 ${ }^{\circ} \mathrm{C} / 100 \mathrm{~m}$. A temperatura máxima registrada aos $30 \mathrm{~m}\left(34,57^{\circ} \mathrm{C}\right)$ ocorreu em dezembro de 2017 e aos $400 \mathrm{~m}(30,85$ ${ }^{\circ} \mathrm{C}$ ) em novembro de 2017. As temperaturas mínimas absolutas ocorreram no mês de julho de 2017, sendo 3,67 (30 $\mathrm{m}$ ) e $4,12{ }^{\circ} \mathrm{C}(400 \mathrm{~m})$. A UR média aos $30 \mathrm{~m}$ de altitude foi de $99,2 \%$, enquanto aos $400 \mathrm{~m}$ foi de $96 \%$. A altitude não influenciou na temperatura e na umidade do ar na referida encosta, pois não houve diferença significativa entre as médias de amplitude diária das variáveis nas duas altitudes.
\end{abstract}

PALAVRAS-CHAVE: Gradiente adiabático, Microclima, Temperatura do ar, Umidade relativa do ar.

\begin{abstract}
The meteorological variables can be influenced by several factors and they suffer modifications according to the atmospheric position, altitude and composition of the vegetation. The objective of work was: a) to characterize the temperature and relative humidity $(\mathrm{RH})$ variation at different altitudes; and $\mathrm{b}$ ) to verify the effect of altitude on these variables. The study area was a stretch of Atlantic rainforest in Guaraqueçaba, Paraná. Two meteorological stations were installed at altitudes of 30 and $400 \mathrm{~m}$ (south face), which collected data on air temperature and RH during the months of May 2017 to April 2018. The average temperature of the period varied from $20.63(30 \mathrm{~m})$ to $19,13^{\circ} \mathrm{C}(400$ $\mathrm{m}$ ), with the thermal reduction rate being $0.34^{\circ} \mathrm{C} / 100 \mathrm{~m}$ of altitudinal elevation. The absolute maximum temperature at $30 \mathrm{~m}$ was $34.57{ }^{\circ} \mathrm{C}$ (December 2017) and at $400 \mathrm{~m}$ it was $30.85^{\circ} \mathrm{C}$ (November 2017). The absolute minimum temperatures occurred in July 2017 , being $3.67(30 \mathrm{~m})$ and $4,12{ }^{\circ} \mathrm{C}(400 \mathrm{~m})$. The mean RH at $30 \mathrm{~m}$ altitude was $99.2 \%$ and at $400 \mathrm{~m}$ it was $96 \%$. The altitude did not influence the temperature and humidity of the air in this gradient, because there was no significant difference between the means of daily amplitude of the variables in the two altitudes.
\end{abstract}

KEYWORDS: Adiabatic gradient, Microclimate, Air temperature, Relative humidity. 


\section{INTRODUÇÃO}

Todos os ecossistemas existentes têm uma relação estrita com o clima da região em que se encontram, onde ambos são mutualmente influenciáveis. Em escala local, a introdução de vegetação pode alterar o microclima e, em escala maior, o clima e suas variações podem ocasionar o deslocamento de espécies e a alteração de ecossistemas (FRITZSONS et al., 2015; TRES, 2016).

O estado do Paraná possui cinco unidades fitogeográficas distintas: Floresta Ombrófila Densa (FOD), Floresta Ombrófila Mista (FOM), Floresta Estacional, Campos e Cerrado (RODERJAN et al., 2002).

A FOD engloba, de forma geral, a costa litorânea e a Serra do Mar. É uma unidade fitogeográfica onde a chuva se distribui ao longo do ano, não apresentando uma estação de seca, além disso, a sua superfície é dominada por elementos arbóreos muito próximos e até sobrepostos, sendo que altas temperaturas estão fortemente relacionadas a este tipo de ambiente (IBGE, 2012).

A FOD é dividida em cinco formações de diferentes composições florísticas e estrutura, que refletem fitofisionomias distintas (RODERJAN et al., 2002). Caglioni (2017) reforça que isso ocorre comumente por conta das condicionantes climáticas e pedológicas, que variam de acordo com a altitude, sendo mais restritivos ao desenvolvimento das árvores quanto maior a altitude.

Para Vanhoni \& Mendonça (2008), a configuração geral do relevo é o fator estático mais importante na caracterização climática da região costeira do Paraná, pois contribui para a existência da grande variedade de climas e de paisagens, devido às diferenças de altitudes e da disposição de suas formas.

De acordo com Soares et al. (2015) e Fritzsons et al. (2016), as variáveis meteorológicas tem uma forte relação com as plantas, tendo influência nas taxas de crescimento, ciclos reprodutivos e diferenciação florística. As variáveis meteorológicas, por sua vez, sofrem a influência de vários fatores, como por exemplo, posição atmosférica, configuração do território, relevo, latitude, altitude, vegetação e efeito da continentalidade (MACIEL et al., 2012).

A temperatura do ar é influenciada pela latitude, longitude, altitude e pela água em nível local, uma vez que a superfície continental se aquece e se resfria mais rapidamente do que a superfície dos corpos d'água; e pelos ventos, visto que transportam ou transmitem ar mais aquecido ou mais frio de uma área para outra, dependendo das características dos gradientes de pressão envolvidos
(FRITZSONS et al., 2016). Além disso, autores como Pinto \& Alfonsi (1974) e Cargnelutti Filho et al. (2006) citam que a temperatura do ar, na faixa litorânea, sofre influência das grandes massas de água.

A umidade do ar, por sua vez, sofre mais com a influência local, sendo que ambientes com presença de vegetação apresentam maior umidade relativa do que ambientes sem vegetação, pois a umidade do ar fica retida sob a cobertura vegetal (GALVANI et al., 2009; DUVAL \& CAMPO, 2017).

Conforme Roderjan et al. (2002), a diminuição das temperaturas médias, aliado à ocorrência de geadas e menor profundidade do solo, é fator determinante na diminuição do número de espécies ao longo do gradiente altitudinal.

Para a serra do mar paranaense, Roderjan \& Grodzki (1999) e Blum et al. (2011), em estudos em altitudes de 930 a $1.150 \mathrm{~m}$ e 400 a $1.000 \mathrm{~m}$, respectivamente, encontraram uma decréscimo da temperatura do ar no decorrer do aumento altitudinal, enquanto que para a umidade relativa do ar, não encontraram relações diretas desta com a altitude.

Este estudo teve como objetivos: a) caracterizar o comportamento da temperatura e umidade relativa do ar em um trecho de 30 a 400 m de altitude da FOD; e b) verificar se há efeito da altitude sobre essas variáveis meteorológicas.

\section{MATERIAL E MÉTODOS}

\section{Caracterização da área de estudo}

A área de estudo está localizada na Reserva Natural Salto Morato (RNSM), nas coordenadas 25ㅇ 10' S e 48우 15' W, de propriedade da Fundação Grupo Boticário de Proteção à Natureza (FGBPN), situada no município de Guaraqueçaba, Paraná.

Segundo o plano de manejo da unidade, a composição geologia da região de estudo é constituída por rochas cristalinas. As altitudes oscilam, em média, entre 150 e 400 $\mathrm{m}$, mas as cotas máximas são superiores a $900 \mathrm{~m}$, enquanto as inferiores são em torno de $20 \mathrm{~m}$. Em relação aos solos, nas áreas de planície e encosta são encontrados os Cambissolos e Cambissolos Háplicos gleicos (FGBPN, 2011).

As formações vegetais existentes na RNSM incluem-se nos domínios da floresta ombrófila densa, nas variações aluvial, submontana, montana e altomontana, (FGBPN, 2011).

De acordo com Alvares et al. (2013), toda a costa do Paraná se encontra no tipo climático $\mathrm{Cfa}$, o qual é 
caracterizado por Soares et al. (2015) como subtropical úmido, com verões quentes, geadas pouco frequentes, sem estação seca definida e com tendência à concentração de chuvas nos meses de dezembro a março.

\section{Coleta de dados}

Foram instaladas duas estações meteorológicas (Figura 1) na encosta sul do morro (fixadas em tubos de PVC, a 1,20 $\mathrm{m}$ da superfície do solo). Os aparelhos utilizados para o registro de dados foram o HOBO Pro v 2 (modelo U23-001), da marca Onset. O registrador HOBO Pro v 2 é um sensor que coleta e armazena dados para o monitoramento do microclima, de forma não supervisionada e de precisão. É composto por um data logger, meio pelo qual os dados são baixados, por meio do software Hoboware. O modelo U23001 coleta dados de umidade relativa e temperatura, com margem de erro de $\pm 0,21{ }^{\circ} \mathrm{C}$ para temperatura e $\pm 2,5 \%$ para umidades de 10 a $90 \%$ e $\pm 3,5 \%$ para umidades abaixo de $10 \%$ e acima de $90 \%$. Os registradores fizeram leituras a cada 1 hora.

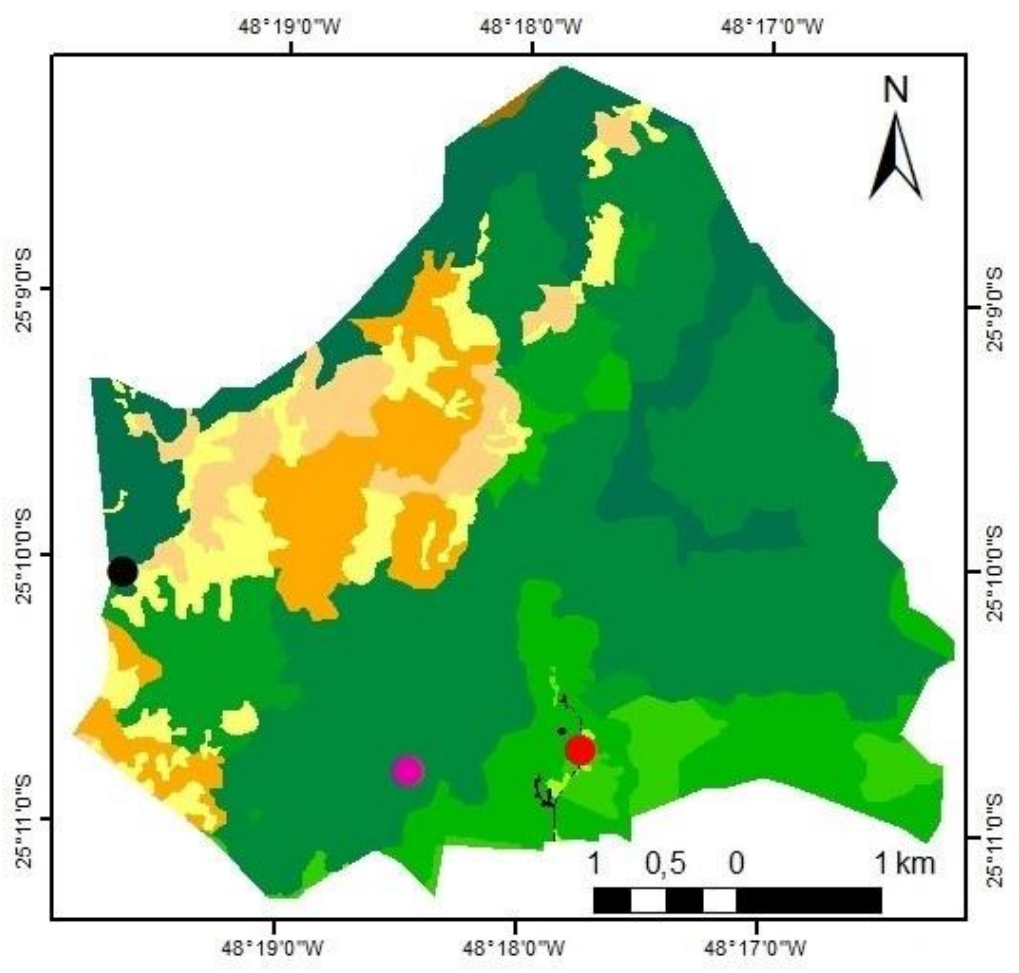

\section{Legenda}

Estação

- So

- 54

Pleno sol

Tipologia

Criciumal

FOD-Secundária avançada

FOD-Sec. inicial arbustiva

FOD-Sec. inicial herbácea

FOD-Sec intermediária

FOD Montana

FODM-Primária muito alterada

FODM-Pri. pouco alterada

FOD Submontana-Pri. alterada

FODSub.-Pri. pouco alterada

FODSub-Secundária

Infrae strutura

Datum SIRGAS 2000

\section{Localização da Reserva Natural Salto Morato}
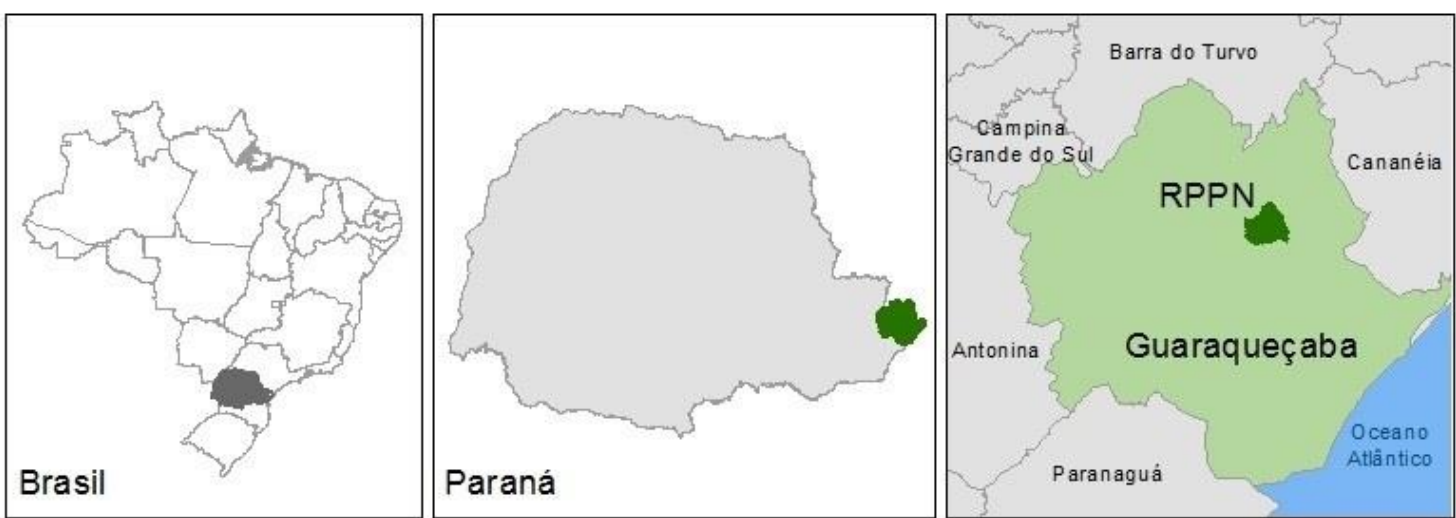

Figura 1. Localização das estações meteorológicas na RNSM: as letras correspondem à orientação da encosta (Sul), enquanto os números altitudes (0: 30 m e 4: 400 m); e Pleno sol corresponde à estação do SIMEPAR (FGBPN, 2014; IBGE, 2016). 
Além das estações meteorológicas instaladas no interior da floresta, foram obtidos os dados da estação meteorológica do SIMEPAR, localizado na base da reserva Salto Morato, a pleno sol, para comparação com os dados coletados no interior da floresta. Ambos os pontos estão localizados na encosta sul, sendo que o ponto SO está localizado em uma altitude de $30 \mathrm{~m}$ e o ponto S4 na altitude de $400 \mathrm{~m}$. O ponto So, por questões logísticas, foi alocado nas proximidades de um corpo de água (30 $\mathrm{m}$ de distância) de aproximadamente 5 metros de largura. 0 monitoramento das variáveis de meteorologia compreendeu os meses de maio de 2017 a abril de 2018.

\section{Análise dos dados}

Os registros obtidos permitiram calcular as temperaturas médias e UR médias diárias, mensais e do período, assim como obter as temperaturas máximas e mínimas absolutas registradas em cada mês.

As médias foram obtidas por meio de média aritmética, a qual, segundo Soares et al. (2015), é a forma mais precisa de se determinar médias. Foi calculado o coeficiente de variação (CV) dos dados meteorológicos registrados pelas estações do interior da floresta, para analisar se as diferenças foram significativas, sendo que quanto menor o CV, mais homogêneos são os dados, seguiu-se a classificação onde CV menores que $10 \%$ são considerados baixos, entre 10 e $20 \%$, médios, entre 20 e $30 \%$, altos, e maiores que $30 \%$, muito altos (PIMENTEL GOMES, 1985).

\section{RESULTADOS E DISCUSSÃO}

Os dados meteorológicos (temperatura média e precipitação) da região de Salto Morato, obtidos pela estação do SIMEPAR, durante o período da pesquisa, são apresentados na Figura 2.

Observa-se que, durante o período analisado, a média anual de temperatura foi de $21,5^{\circ} \mathrm{C}$, sendo o período mais quente os meses de dezembro de 2017 e janeiro de 2018 (25,8 e $24,9^{\circ} \mathrm{C}$, respectivamente) e o período mais frio os meses de junho e julho de 2017 , com 17,3 e $16,3{ }^{\circ} \mathrm{C}$, respectivamente.

Em relação a precipitação, o volume total precipitado no período foi de $2.003 \mathrm{~mm}$ dos quais $56 \%$ (1.132 $\mathrm{mm}$ ) se concentraram nos meses de dezembro a março. É provável que a precipitação anual tenha sido ainda maior, pois, após uma chuva de $190 \mathrm{~mm}$ no dia 11 de fevereiro de 2018, a estação do SIMEPAR apresentou uma falha e não registrou a precipitação por 22 dias seguidos. Ainda houve outros dias com falhas no registro de precipitação, totalizando 25 dias sem registros de precipitação.

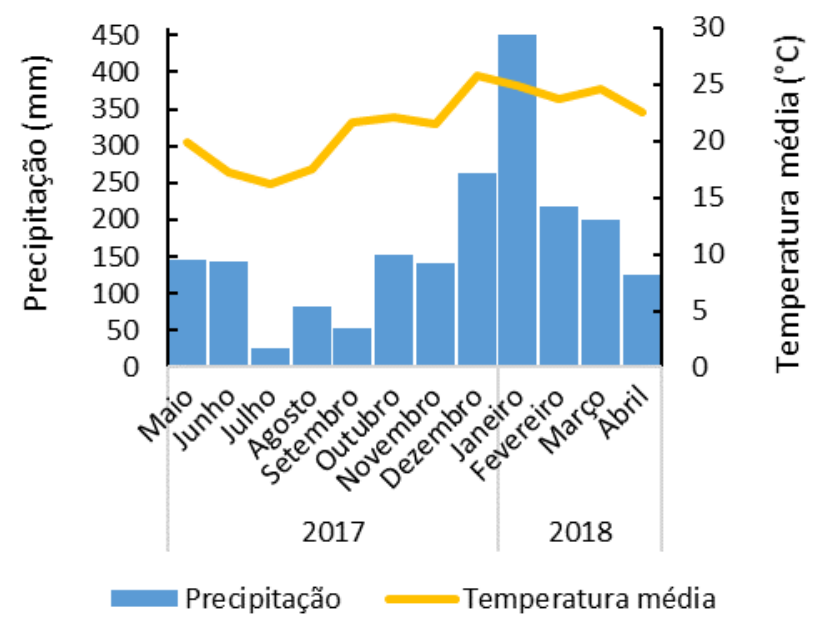

Figura 2. Temperatura média e precipitação total, de maio de 2017 a abril de 2018, para RNSM (SIMEPAR, 2018).

\section{Comportamento da temperatura do ar}

Na Figura 3 são apresentadas as temperaturas médias diárias do ano de pesquisa, para as estações localizadas no interior da floresta. Observando esses dados, juntamente com os dados da estação à pleno sol, e seguindo a classificação climática de Köppen, reafirma-se que a área de estudo se enquadra no tipo climático Cfa, subtropical úmido.

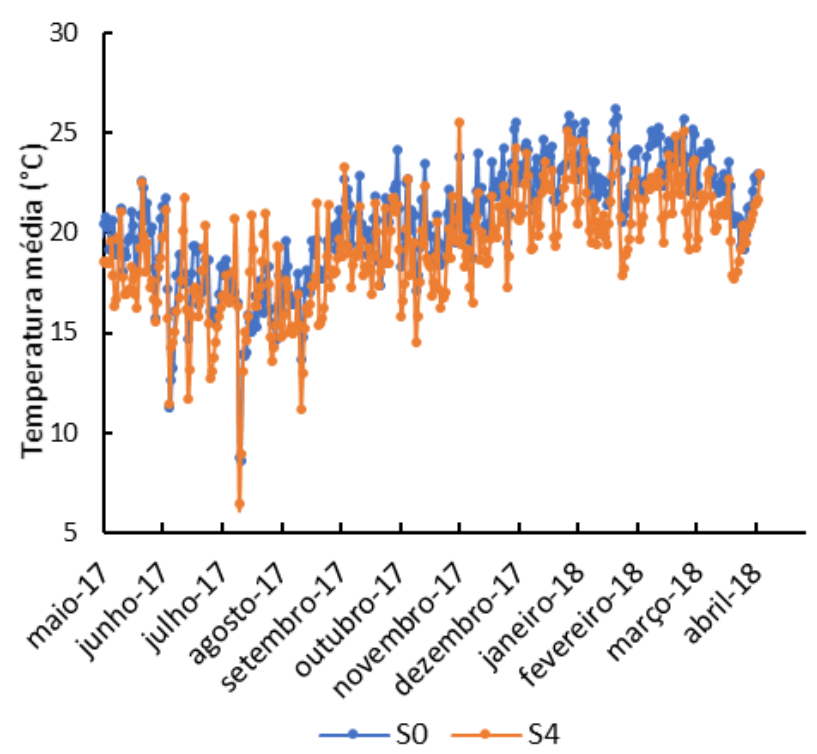

Figura 3. Temperaturas médias diárias, para o período de maio de 2017 a abril de 2018, para estação S0 (30 m s.n.m.) e $\$ 4$ (400 m s.n.m.). 
Nota-se que as temperaturas médias mais frias ocorreram nos meses de junho a agosto, sendo que no mês mais frio (julho), não ultrapassou os $18^{\circ} \mathrm{C}$ em nenhuma das estações. Para as temperaturas médias mais quentes, observa-se que ocorreram nos meses de dezembro de 2017 a março de 2018 e foram superiores a $22{ }^{\circ} \mathrm{C}$. As médias das temperaturas mais altas ocorreram em meses diferentes em cada estação, sendo dezembro de 2017 na estação a pleno sol, janeiro de 2018 para a estação S4, e no mês de março de 2018 para a estação So.

Conforme abordado por Maack (2017), as temperaturas mais baixas realmente ocorrem no mês de julho para o estado do Paraná, mês o qual nos ambientes montanos e altomontanos ocorrem geadas noturnas mais frequentes. Contudo, as temperaturas médias mais altas, segundo o autor, deveriam ocorrer no mês de janeiro, retardando-se no máximo até fevereiro.

A ocorrência de temperaturas mais altas no mês de março para a estação meteorológica SO pode ser explicada pela menor precipitação nesse mês (199 mm), quando comparados com os meses de janeiro e fevereiro (451 e $219 \mathrm{~mm}$, respectivamente). Segundo Silva (2012), a precipitação promove um efeito negativo na temperatura, sendo que quanto maior a precipitação, menor a temperatura média, visto que após eventos de precipitação a temperatura sofre amenização.

É possível observar ainda, na Figura 3, que a dispersão das temperaturas médias diárias entre as estações S0 e S4 é maior nos meses de verão seguido pelos meses da primavera, enquanto que nos meses de inverno a dispersão da temperatura média é notavelmente menor, chegando as linhas de dispersão a se sobreporem.

Ainda assim, as correlações negativas entre temperatura média e altitude foram observadas em todo o período, sendo que o maior gradiente de variação da temperatura média a cada 100 metros no interior da floresta foi de $0,52{ }^{\circ} \mathrm{C}$ no mês de março de 2018 (CV = $6,41 \%$ ) e o menor gradiente de $0,04^{\circ} \mathrm{C}$, no mês de junho de 2017 (CV =0,76\%). A tendência da temperatura em sofrer maior influência da altitude nos meses mais quentes (primavera e verão) do que nos meses de outono-inverno corrobora com os resultados encontrados por Cargnelutti Filho et al. (2006), Vanhoni \& Mendonça (2008) e Fritzsons et al. (2015).

Isso ocorre pelo fato de que no outono-inverno ocorrem inversões térmicas, que fazem com que a temperatura do ar, nos vales, permaneça mais fria por um período maior tempo. Como consequência, as menores temperaturas distribuem-se melhor no espaço geográfico e as regiões de maior altitude não se diferenciam tanto das outras regiões (FRITZSONS et al., 2015). Para todo o período analisado, o decréscimo da temperatura de $0,34{ }^{\circ} \mathrm{C}$ a cada $100 \mathrm{~m}$ de altitude ( $\mathrm{CV}=4,71 \%$ ).

Soares et al. (2015) citam que a temperatura cai de forma proporcional com a elevação vertical, em virtude da redução na pressão atmosférica, fenômeno que recebe o nome de esfriamento adiabático. Como um valor geral, Ometto (1981) afirma que o gradiente adiabático seco (quando o ar está seco) é de aproximadamente $1^{\circ} \mathrm{C}$ a cada $100 \mathrm{~m}$, enquanto que o gradiente adiabático úmido (quando o ar está saturado) é cerca de $0,6^{\circ} \mathrm{C}$ para cada 100 $\mathrm{m}$ de altitude. Para o Paraná, Fritzsons et al. (2008) encontraram um decréscimo de $0,79^{\circ} \mathrm{C} / 100 \mathrm{~m}$

$O$ resultado encontrado nesse estudo é inferior aos encontrados por Maack (2017), que considerando somente a Serra do Mar do estado, encontrou um resfriamento de $0,5{ }^{\circ} \mathrm{C}$ a cada $100 \mathrm{~m}$ de elevação da Roderjan \& Grodzki (1999) na Serra da Baitaca, que obtiveram o índice de $0,56^{\circ} \mathrm{C}$; e por Blum et al. (2011) para a Serra da Prata, que registraram uma redução de $0,44{ }^{\circ} \mathrm{C}$ a cada $100 \mathrm{~m}$.

Assim, como observado por Blum et al. (2011), a menor variação térmica com a altitude pode ser devido à sua pequena distância em relação ao mar, tendo em vista que a área de estudo dessa pesquisa está a aproximadamente $15 \mathrm{~km}$ da baía de Guaraqueçaba. De acordo com Correa et al. (2017), as variações térmicas em áreas próximas do oceano tendem a ser menores, reduzindo a amplitude anual e, de forma inversa, quanto mais longe do mar a tendência é que a amplitude térmica aumente, efeito conhecido como continentalidade, que também é citado por autores como Pinto \& Afonsi (1974), Fritzsons et al. (2008), Vanhoni \& Mendonça (2008) e Maciel et al. (2012).

Outro fator a ser considerado é a proximidade do ponto So com um corpo d'água. Da mesma forma que ocorre amenização das temperaturas em virtude da ação atenuante do oceano, as temperaturas também tendem a ser mais baixas próximo a corpos de água, devido à maior umidade do ar nesses locais. Consequentemente, pela redução da temperatura neste local, o gradiente térmico vertical registrado entre os pontos é menor.

Além disso, de acordo com Soares et al. (2015) e Torres et al. (2016), a face sul, onde foram instaladas as estações SO e S4, apresenta maior umidade relativa, em virtude do maior período de deposição de orvalho, que atua como um efeito "tampão", fazendo diminuir as alterações térmicas. No hemisfério sul a vertente de exposição que mais recebe insolação é a norte, seguida pelas vertentes oeste, leste e sul, ou seja, as vertentes orientadas para sul recebem menor incidência de radiação solar direta, o que, 
certamente exerce grande influência no microclima desses locais.

De modo geral, a temperatura decresceu com o aumento altimétrico, todavia, o gradiente de redução foi menor que o esperado em virtude da maritimidade e proximidade com corpos da água.

Na Figura 4 estão apresentados os valores diários das temperaturas máximas e mínimas absolutas, para as estações meteorológicas S0 e S4, durante o período de maio de 2017 a abril de 2018. Nela é possível observar que as temperaturas máximas registradas mais altas ocorrem de novembro de 2017 a fevereiro de 2018. No mês de dezembro de 2017 ocorreram as maiores amplitudes térmicas entre as estações meteorológicas.

A máxima absoluta do período ocorreu no mês de dezembro, sendo de $34,57^{\circ} \mathrm{C}$ para estação So e $30,77^{\circ} \mathrm{C}$ para estação S4, ambas ocorreram no dia 17, às $14 \mathrm{~h}$. Nesse mesmo horário a temperatura na estação a pleno sol foi de $43,80^{\circ} \mathrm{C}$, uma diferença de $9,23^{\circ} \mathrm{C}$ quando comparada com a estação localizada na mesma altitude, no interior da floresta, chegando a uma diferença de $13,03{ }^{\circ} \mathrm{C}$ quando comparada com os dados da estação S4.

Ainda observando as máximas, nota-se que em alguns pontos a temperatura máxima registrada aos $400 \mathrm{~m}$ de altitude foi maior que aos $30 \mathrm{~m}$ de altitude. Essa situação ocorreu principalmente nos meses de julho e agosto, mas com ocorrência esporádica nos meses de junho e abril.

Analisando as 8.760 horas de registros das estações S0 e S4, observa-se que cerca de $18 \%$ registraram temperaturas maiores na altitude de $400 \mathrm{~m}$. Maack (2017) afirma que durante a noite, nas camadas inferiores, a temperatura do ar aumenta com a altitude devido ao fato de que ao anoitecer o ar frio que se forma acima do solo, em altitudes elevadas, acompanha determinadas linhas topográficas e desliza para os vales. Separando os dados de temperatura do ar em dia (das 6 às $18 \mathrm{~h}$ ) e noite (das 19 às $5 \mathrm{~h}$ ) constata-se que, durante o dia o gradiente térmico é de $0,48{ }^{\circ} \mathrm{C} / 100 \mathrm{~m}$ de altitude, enquanto que durante a noite, esse valor cai para $0,19^{\circ} \mathrm{C} / 100 \mathrm{~m}$.

O período em que ocorrem as temperaturas máximas corrobora com o período normal descrito pelo mesmo autor, que afirma que a máxima absoluta, em virtude da seca, pode ser verificada a partir de outubro, se estendendo até março.

Em relação às temperaturas mínimas absolutas, de forma menos acentuada, a cobertura florestal também ameniza as temperaturas mínimas. Nesse estudo todas as mínimas absolutas ocorreram no mês de julho de 2017, assim como encontrado por autores como Vanhoni \& Mendonça (2008) e Blum et al. (2011). A menor temperatura registrada na estação a pleno sol foi de 2,10 ${ }^{\circ} \mathrm{C}$, enquanto que nas estações $\mathrm{S} 0$ e $\mathrm{S} 4$ foram registradas as temperaturas de 3,67 e $4,12{ }^{\circ} \mathrm{C}$, respectivamente, sendo que todas as mínimas absolutas ocorreram no dia 19 de julho as $5 \mathrm{~h}$ da madrugada.
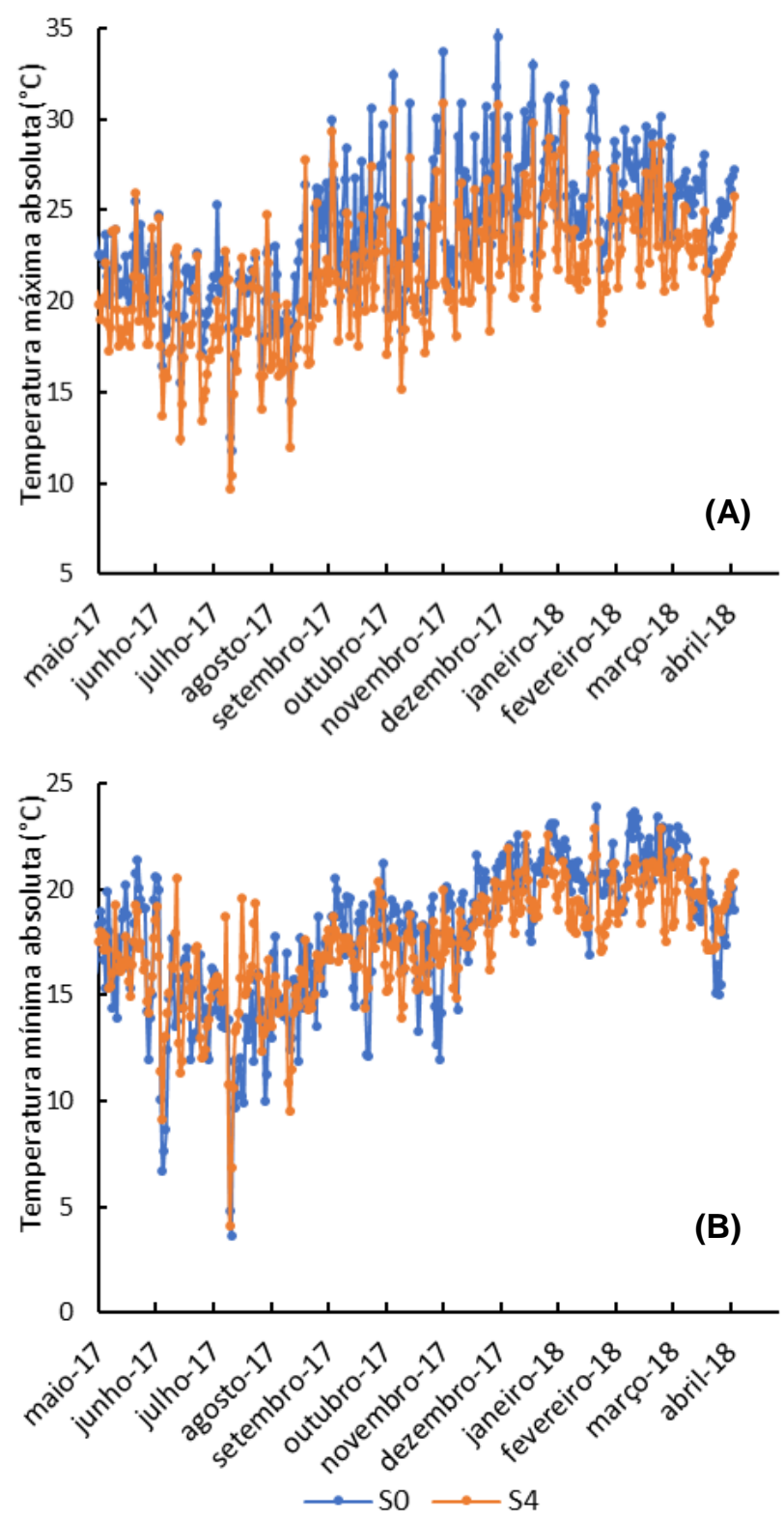

Figura 4. (A) temperatura máxima e (B) mínima para o período de maio de 2017 a abril de 2018, para estação S0 (30 m s.n.m.) e S4 (400 m s.n.m.).

Diferentemente do comportamento das temperaturas médias e máximas absolutas diárias, é possível notar que para grande parte de todo o período observado as menores temperaturas mínimas ocorreram aos $30 \mathrm{~m}$ de altitude, ou seja, para esses dias a temperatura mínima aumentou com a altitude, comportamento contrário ao esperado, quando se observa a tendência das médias e máximas absolutas. Para Fritzsons et al. (2008, 2016), os 
fundos de vale, incluindo as margens de rios e proximidades das escarpas são áreas climaticamente distintas, pois é onde ocorrem as maiores amplitudes térmicas diárias, sendo assim, a presença do rio próximo à estação SO acarretou em temperaturas mínimas mais baixas, quando comparadas às temperaturas registradas a $400 \mathrm{~m}$ de altitude.

\section{Comportamento da umidade relativa do ar}

A umidade relativa registrada para o período, considerando os resultados de Galvani et al. (2009), que encontraram UR média de $80 \%$ para áreas de FOD, foi considerada alta para as estações meteorológicas do interior da floresta. Para a altitude de $30 \mathrm{~m}$ a UR média foi de $99,2 \%$ e para a altitude de $400 \mathrm{~m}$ a UR média foi de 96,0\% (Tabela 1).
Os valores obtidos para a UR (estações S0 e S4), tanto média quanto máximas e mínimas absolutas médias, também são consideravelmente mais elevados que os encontrados por Roderjan \& Grodzki (1999), Falcão et al. (2010) e Blum et al. (2011), sendo que, para altitude de 30 $\mathrm{m}$, em mais da metade dos dias (250 dias) a umidade relativa do ar foi igual a $100 \%$, e para a altitude de $400 \mathrm{~m}$, isso ocorreu para quase um terço dos dias (115 dias).

Dos 250 dias de UR com 100\% na estação S0, todos ocorreram de forma seguida (pelo menos 2 dias seguidos), sendo que 95 dias ocorrem consecutivamente nos meses de maio a julho de 2017. Para a estação S4, o maior número de dias seguidos com UR igual a $100 \%$ foi 10 e ocorreu no mês de março de 2018. Blum et al. (2011) encontraram um máximo de 9 dias consecutivos de UR igual a 100\% e Roderjan \& Grodzki (1999), 5 dias. Não houve dias de UR igual a $100 \%$ na estação a pleno sol.

Tabela 1. Umidade relativa do ar (\%) para o período de maio de 2017 a abril de 2018 para estação S0 (30 m s.n.m.) e S4 (400 m s.n.m.).

\begin{tabular}{|c|c|c|c|c|c|c|c|c|c|}
\hline \multirow{3}{*}{ Ano } & \multirow[b]{3}{*}{ Mês } & \multicolumn{4}{|c|}{ so } & \multicolumn{4}{|c|}{ S4 } \\
\hline & & \multicolumn{8}{|c|}{ Umidade relativa do ar (\%) } \\
\hline & & Média & $\begin{array}{c}\text { Média das } \\
\text { máximas } \\
\text { absolutas }\end{array}$ & $\begin{array}{l}\text { Média das } \\
\text { mínimas } \\
\text { absolutas }\end{array}$ & $\begin{array}{l}\text { Dias com } \\
\text { UR } 100 \%\end{array}$ & Média & $\begin{array}{l}\text { Média das } \\
\text { máximas } \\
\text { absolutas }\end{array}$ & $\begin{array}{l}\text { Média das } \\
\text { mínimas } \\
\text { absolutas }\end{array}$ & $\begin{array}{l}\text { Dias com } \\
\text { UR } 100 \%\end{array}$ \\
\hline \multirow{8}{*}{$\stackrel{\stackrel{\ominus}{\ominus}}{V}$} & Maio & 100,0 & 100,0 & 99,9 & 29 & 98,3 & 99,9 & 95,4 & 14 \\
\hline & Junho & 100,0 & 100,0 & 100,0 & 30 & 93,1 & 98,0 & 86,0 & 10 \\
\hline & Julho & 100,0 & 100,0 & 99,7 & 25 & 94,0 & 98,2 & 86,7 & 6 \\
\hline & Agosto & 99,7 & 100,0 & 97,4 & 19 & 94,0 & 97,7 & 87,9 & 8 \\
\hline & Setembro & 98,6 & 100,0 & 91,6 & 10 & 96,5 & 100,0 & 87,0 & 6 \\
\hline & Outubro & 98,6 & 100,0 & 92,0 & 16 & 94,4 & 99,2 & 85,8 & 7 \\
\hline & Novembro & 96,5 & 100,0 & 85,6 & 13 & 93,5 & 99,1 & 85,2 & 11 \\
\hline & Dezembro & 98,5 & 100,0 & 93,3 & 19 & 98,0 & 99,9 & 93,5 & 15 \\
\hline \multirow{5}{*}{$\underset{\infty}{\stackrel{\sim}{\sim}}$} & Janeiro & 98,8 & 100,0 & 94,2 & 20 & 95,5 & 99,3 & 88,4 & 9 \\
\hline & Fevereiro & 99,5 & 100,0 & 97,0 & 20 & 97,7 & 99,9 & 91,9 & 7 \\
\hline & Março & 100,0 & 100,0 & 99,6 & 26 & 98,6 & 99,9 & 94,8 & 18 \\
\hline & Abril & 99,8 & 100,0 & 98,7 & 23 & 97,4 & 99,7 & 91,5 & 4 \\
\hline & Média & 99,2 & 100,0 & 95,7 & 20,8 & 96,0 & 99,2 & 89,5 & 9,6 \\
\hline
\end{tabular}

A menor média mensal registrada aos $30 \mathrm{~m}$ de altitude foi de $96,5 \%$ (novembro de 2017 ) e foi de $93,1 \%$ na altitude de $400 \mathrm{~m}$, no mês de junho de 2017. Para estação a pleno sol a média foi de $88,3 \%$. As menores URs mínimas médias ocorreram no mês de novembro de 2017 para as duas altitudes e foram de 85,6 e $85,2 \%$, respectivamente. Para Serra da Prata, Blum et al. (2011) encontraram as URs mínimas médias mais baixas (71,6\% aos $400 \mathrm{~m}$ e $60,1 \%$ aos $1.000 \mathrm{~m}$ ) no mês de agosto. As URs máximas médias chegaram a $100 \%$ em todos os meses de observação na altitude de $30 \mathrm{~m}$ e, na altitude de $\mathbf{4 0 0} \mathrm{m}$, as URs máximas médias foram maiores que $97 \%$.

Os altos valores encontrados para estação SO, assim como o grande número de dias seguidos com UR igual a $100 \%$ nesse ambiente, estão ligados com a proximidade dessa estação meteorológica com o rio, como citado anteriormente.

Assim como para a temperatura do ar, as URs não sofreram grande influência pela altitude no período de estudo, uma vez que a amplitude média diária de UR entre 
as duas altitudes foi de 3,2\% (CV = 2,32\%), 0,8\% (CV < 1) para as máximas médias diárias e $6,1 \%$ para as mínimas médias diárias ( $C V=4,66 \%$ ).

A ocorrência das chamadas chuvas orográficas em áreas litorâneas, certamente garante altas taxas de UR do ar na serra do mar. Essas chuvas ocorrem quando há o encontro da massa de ar quente e úmida com uma montanha, forçando o ar a se elevar ocasionando a precipitação (MAACK, 2017). Vale ressaltar também que as estações foram instaladas no interior da floresta, a 1,20 m do solo, e como observado por Falcão et al. (2010) e Blum et al. (2011), sofreram influência da ação protetora do dossel da floresta, que ameniza a movimentação das massas de ar e proporciona períodos mais longos de alta umidade.

Duval \& Campo (2017) mostram que a UR do ar apresenta uma alta relação com aspectos como uso do solo, cobertura vegetal e estrutura do dossel da vegetação, ou seja, possivelmente a UR do ar apresente uma maior relação com o nível escalar microclimático do que com o nível altimétrico.

\section{CONCLUSÕES}

- A temperatura média e máxima absoluta durante o período de maio de 2017 a abril de 2018 foram relativamente maiores na altitude de $30 \mathrm{~m}$ do que na altitude de $400 \mathrm{~m}$, cujas diferenças estão relacionadas com a elevação altimétrica.

- A temperatura mínima absoluta foi relativamente menor na altitude de $30 \mathrm{~m}$ do que aos $400 \mathrm{~m}$, estando esse resultado relacionado com a presença de um curso d'água próximo à estação na altitude de $30 \mathrm{~m}$, o que propiciou a ocorrência de temperaturas menores.

- $O$ gradiente adiabático $\left(0,34{ }^{\circ} \mathrm{C} / 100 \mathrm{~m}\right)$ foi considerado baixo. $\mathrm{O}$ resultado pode ser atribuído ao efeito atenuador do oceano, que acarreta em uma menor amplitude térmica, e pela influência do rio no ambiente onde foi instalada a estação SO.

- Quanto a média da umidade relativa do ar, ela foi elevada em ambas estações, ressaltando-se o número de dias seguidos em que a UR se manteve em $100 \%$. Os altos valores encontrados são atribuídos às chuvas orográficas. Particularmente, a umidade do ar registrada aos $30 \mathrm{~m}$ de altitude sofre influência do rio.

\section{REFERÊNCIAS}

ALVARES, C.A. et al. Köppen's climate classification map for Brazil.
Meteorologische Zeitschrift, v.22, p.711-728, 2013.

BLUM, C.T. et al. O clima e sua influência na distribuição da floresta ombrófila densa na Serra da Prata, Morretes, Paraná. Floresta, v.41, n.3, p.589-598, 2011.

CAGLIONI, E. Gradientes ambientais e sua influência na variação da estrutura da vegetação no parque botânico do Morro do Baú - SC. 2017. 149p. (Tese de doutorado).

CARGNELUTTI FILHO, A. et al. Altitude e coordenadas geográficas na estimativa da temperatura mínima média decendial do ar no Estado do Rio Grande do Sul. Pesquisa Agropecuária Brasileira, v.41, n.6, p.893-901, 2006.

DUVAL, V.S.; CAMPO, A.M. Variaciones microclimáticas en el interior y exterior del bosque de caldén (Prosopis caldenia), Argentina. Cuadernos de Geografía, v.26, n.1, p.37-49, 2017.

FALCÃO, R.M. et al. Análise da variação da umidade relativa do ar do pico da bandeira, Parque Nacional Alto Caparaó, Brasil. In: Seminário ibero-americano de geografia física, v.6, p.1-10, 2010.

FGBPN - FUNDAÇÃO GRUPO BOTICÁRIO DE PROTEÇÃO À NATUREZA. Plano de manejo da Reserva Natural Salto Morato Guaraqueçaba, v. 1. Curitiba, 2011.

FRITZSONS, E. et al. Relação entre altitude e temperatura: uma contribuição ao zoneamento climático no estado do Paraná. Revista de Estudos Ambientais, v.10, n.1, p.49-64, 2008.

FRITZSONS, E. et al. Altitude e temperatura: estudo do gradiente térmico no Rio Grande do Sul. Revista Brasileira de Climatologia, v.16, p.108-119, 2015.

FRITZSONS, E. et al. Relação entre altitude e temperatura: uma contribuição ao zoneamento climático no estado de Santa Catarina, Brasil. Revista Brasileira de Climatologia, v.18, p.80-92, 2016.

GALVANI, E. et al. Relação entre umidade relativa do ar, cobertura vegetal e uso do solo no Parque Estadual de Intervales (PEI) e seu entorno, São Paulo, Brasil. 12 Encontro de Geógrafos da América Latina - EGAL, 2009.

IBGE - INSTITUTO BRASILEIRO DE GEOGRAFIA E ESTATÍSTICA. Brasil: divisão político-administrativo. Rio de Janeiro: IBGE, 2016. Disponível em: https://mapas.ibge.gov.br/bases-ereferenciais/bases-cartograficas/malhas-digitais

IBGE - INSTITUTO BRASILEIRO DE GEOGRAFIA E ESTATÍSTICA. Manual técnico da vegetação brasileira. Série Manuais Técnicos em Geociências, 2.ed. Rio de Janeiro: IBGE, 2012. Disponível em: https://biblioteca.ibge.gov.br/visualizacao/livros/liv63011.pdf

MAACK, R. Geografia física do estado do Paraná. 4.ed. Ponta Grossa: Ed. UEPG, 2017.

MACIEL, A.S. et al. A análise da influência da altitude na temperatura e na precipitação da mesorregião Norte de Minas Minas Gerais. Rev Geonorte, v.2, p.250-261, 2012.

OMETTO. J. C. Bioclimatologia vegetal. São Paulo: Agronômica Ceres,1981. 
PIMENTEL GOMES, F. Curso de estatística experimental. São Paulo: Nobel, 1985.

PINTO, H.S.; ALFONSI, R.R. Estimativa das temperaturas médias, máximas e mínimas mensais no Estado do Paraná, em função de altitude e latitude. Caderno de Ciências da Terra, v.52, p.1-28, 1974.

RODERJAN, C.V. et al. As unidades fitogeográficas do Estado do Paraná. Ciência \& Ambiente, v.24, n.1, p.75-92, 2002.

RODERJAN, C.V.; GRODZKI, L. Acompanhamento meteorológico em um ambiente de floresta ombrófila densa altomontana no Morro Anhangava, município de Quatro Barras - PR, no ano de 1993. Cadernos da Biodiversidade, v.2, n.1, p.27-34, 1999.

SILVA, D.A. A função da precipitação no conforto do clima urbano da cidade de Manaus. Revista Geonorte, v.2, n.9, p.22-40, 2012.

SIMEPAR - SISTEMA METEOROLOGICO DO PARANÁ. Dados meteorológicos da estação Salto Morato [mensagem pessoal]. Mensagem recebida por <franpajewski@yahoo.com.br> em junho de 2018.

SOARES, R.V. et al. Meteorologia e climatologia florestal. Curitiba: 2015.

TORRES, F.T.P. et al. Influência do relevo nos incêndios em vegetação em Juiz de Fora (MG). GEOgraphia, v.18, n.36, p.170182, 2016.

TRES, A. Classificação climática para o Brasil segundo as zonas de vida de Holdridge. 2016. 89p. (Dissertação de mestrado).

VANHONI, F.; MENDONÇA, F. O clima do litoral do estado do Paraná. Revista brasileira de climatologia, v.3, p.49-63, 2008. 